ausführung entweichen, ist ausgeschlossen, da das Rohr, durch das die Kohlensäure in den Trockenapparat geht, nicht mehr wesentlich warm wird. Will man aber die Gesammtsäuren und die ganze Seife bestimmen, so geschieht dies entweder in der bequemen $\mathrm{Hu}$ genberg' schen Bürette ${ }^{1}$ ) oder auch in einem einfachen Scheidetrichter, in dem eine gewogene Menge der Seife mit Säure und Äther vorsichtig zersetzt wird. Man lässt die saure Lauge dann ab und wäscht mit wenig kaltem Wasser nach. Alsdann kann man die ätherische Lösung ebenfalls direct durch Neutralisation mit gestellter alkoholischer Lauge in die "Reinseife" überführen, diese wie oben, zur Wägung bringen und daraus den "Gesammtfettsäuregehalt" bestimmen.

\section{Chemische Leistungen}

der Mikroorganismen im Gewerbe.

\section{Von C. Wehmer.}

Gewerblich wichtige chemische Leistungen von Mikroorganismen kennt man zur Zeit in grösserer Zahl; am längsten bekannt und wichtigsten ist die Thätigkeit der Hefen im Alkoholgährungsgewerbe, mehr zurück treten die - übrigens ungleich vielseitigereu - Bakterien, noch mehr die eigentlichen Pilze (Mycelpilze). Man kann die hierher gebörigen Processe in 3 Hauptgruppen ordnen, von denen die erste den Chemiker besonders angeht: 1. Umbildung von Stärke oder Zucker in Alkohol und organische Säuren, 2. Umwandlung von Stickstoffverbindungen (Harnstoff, Ammoniak u. a.), 3. Stoffzersetzungen verschiedener Art.

Die Alkoholbildung aus Zucker ist vorzugsweise eine Eigenthümlichkeit mancher Hefepilze, sie findet sich aber auch bei Bakterien und Mycelpilzen, Alkohol ist überhaupt ein verbreitetes pflanzliches Stoffwechselproduct. Technisch arbeitet man ausschliesslich mit den Zucker spielend leicht umwandelnden Hefen (Brauerei, Brennerei, Weinbereitung). Offenbar ist dieser Process ziemlich complicirt (Nebenproducte), unähnlich den sogenannten Enzym wirkungen (Hydrolysen), und auch bislang von der plasmatischen Leibessubstanz der Hefezelle nicht abgetrennt; die Entstehung des sauerstoffarmen Äthylalkohols aus dem Zucker liegt hinsichtlich des Chemismus noch keineswegs klar. Seine technische Herstellung auf rein chemischem Wege scheint bislang ausgeschlossen, wäre aber gegebenen Falls,

1) Zeitschr. öffentl. Chem. 1898, 163. wenn gleich wohlfeil, von einschneidender Wirkung.

Die Bildung organischer Säuren finden wir bei manchen Bakterien und einigen Pilzen. Erstere cultivirt man in der Technik bei Herstellung von Essig, Milchsäure, Buttersäure; die Essiggährung ist eine ziemlich glatte Oxydation des Alkohols; solche Bakterien vermögen auch andere Substanzen zu oxydiren (Zucker, höhere Alkohole). Ihre Zahl ist neuerdings im Wachsen, auch sucht man die bislang ziemlich rohe Gäbrung zu verbessern (Reinculturen bestimmter Rassen). Wichtiger ist die Erzeugung von Milchsäure durch Bakterien, die sowohl in der chemischen Technik zur Herstellung der Säure wie als Nebenprocess in manchen Gewerben (Gerberei, Brennerei, Molkerei u.a.) eine Rolle spielt. Fast die ganze Reihe der spontanen Säuerungsvorgänge (Einsäuern von Futtermitteln wie Heu, Schnitzel, Treber, Rübenblätter, von Sauerkraut u. a.) gehört hierher; die $\mathrm{Zahl}$ der dabei thätigen Bakterien scheint weit grösser zu sein, als man früher vermuthete. Fast regelmässig wird die Milchsäuregährung später durch die Buttersäuregährung abgelöst(technische Darstellung), wobei andere Bakterienarten in Thätigkeit treten. Der Vorgang ist weniger glatt, und gleichfalls wohl nur als Stoffwechselwirkung verständlich, im Übrigen wissenschaftlich dürftig studirt. Umformung von Zucker in Citronensäure und ebenso in Oxalsäure wird durch einige Mycelpilze bewirkt; beide Processe sind ausgesprochene Oxydationen unterstarkem Verzehr atmosphärischen Sauerstoffs und von sehr glattem Verlauf. Neuerdings will man für derartige Vorgänge bekanntlich gleichfalls Enzyme ("Oxydasen") verantwortlich machen, die Meinungen sind darüber aber noch durchaus getheilt.

Eine notorische Enzymwirkung ist die Zuckerbildung aus Stärke durch Mycelpilze, die von technischer Bedeutung allerdings bislang nur im Auslande (Ostasien) ist, wo Pilze im Gährungsgewerbe die Rolle unseres Malzes übernehmen (Verarbeitung von Reis auf Sake in Japan, auf Arrak, A]kohol in China, Hinterindien, Java). Am bekanntesten geworden sind zwei Arten, Aspergillus Oryzae und Mucor Rouxii (= Amylomyces), die man neuerdings auch bei uns versuchsweise anwendet. Bedauerlich ist, dass auch in dieser Richtung die Anregung erst vom Auslande kommen musste und nicht für das Studium der wichtigen und wissenschaftlich interessanten Pilze gerade so gut staatliche Laboratorien, wie solche für Hefen und Bakterien existiren, vorhanden sind. Das den Mucor benützende Amyloverfahren soll in 
Frankreich, Belgien, Italien, Spanien u. A. in weiterem Umfange zumal in grossen Brennereien eingeführt sein; es löst die Aufgabe, sterile Maismaischen von $1000 \mathrm{hl}$ und mehr durch minimale Mengen von Reinculturen in wenigen Tagen zu verzuckern und zu vergäbren; nach den anfänglich gemachten Angaben sollte der Mucor beides durchführen, heute verwendet man gleichzeitig Hefe. Über diese verzuckernden Pilzenzyme ist noch wenig Genaueres bekannt, durch Auslaugen mit Wasser sind sie aber von dem Plasma der Zelle abtrennbar und so gesondert auf ihre Wirkung zu untersuchen.

In die zweite Hauptgruppe gewerblicher Mikroorganismenwirkungen zählen wir hier die Umformung von Stickstoffrerbindungen, unter denen die Ammoniakbildung aus Harnstoff (ammoniakalische Gährung) und seine Umformung in Salpetersäure (Nitrification) obenan stehen; erstere gilt als Hydrolyse, letztere ist Oxydation. Das sind fast ausschliesslich Bakterienleistungen, wichtig zumal für die Landwirthschaft. Auch Hygiene (Abwässerreinigung) und Chemie (Salpeter) haben aber Interesse daran. Dahin gehört auch die Fixirung des atmosphärischen Stickstoffs durch Knöllchenund Bodenbakterien (Nitrogin, Alinit), ein noch heute ziemlich dunkler Vorgang, weiterhin die Reduction des Salpeters im Ackerboden (Denitrification), alles wichtige agriculturchemische Probleme, in den letzten Decennien intensiv studirt, reich an Controversen und nicht frei von mancherlei Verirrungen.

Die dritte Hauptgruppe umfasst eine ganze Zone biochemischer Processe, bei denen im Ganzen die substanzzerstörende Wirkung der Mikroorganismen - meist Bakterien - im Vordergrunde stebt; einiges müssen wir auch mehr zwangsweise hier unterbringen (Käsereifung). Ihre gewerbliche Rolle ist minder hervortretend, theilweise auch durch rein chemische Mittel ersetzt. Enzym- und Stoffwechselwirkung greifen da vielfach ineinander; nur einiges soll hier gestreift werden. $Z u$ nennen sind die verschiedenen Röttungsprocesse (Elachs, Hanf) und fauligen Gährungen (Gerberei, Stärkegewinnung, Knochenkohleregeneration), wo durch Mikroorganismen Störendes beseitigt wird. Letzteres kommt jedenfalls auch mit in Frage bei der Vietsbohnengährung, der Tabaksfermentation - einem ausgesprochen biologisch-chemischen Vorgange - und einigen weiteren minder gut bekannten Processen (Gährung des Opiums, der Cacaobohnen u. a.). In bestimmten Fällen nützt aucb hier das entstandene Product, so die
Gasentwicklung beim Treiben des Brodteiges durch Presshefe; dahin könnte man vielleicht auch das dem fermentirten Tabaksblatt, dem verbutterten Rahm oder der reifenden Käsemasse mitgetheilte Aroma rechnen, wenngleich die letztgenannten Vorgänge noch keineswegs bakteriologisch ganz klar liegen. Aucb hier ist die Reincultur der bezüglichen Organismen lebhaft im Fortschritt begriffen (Butterbakterien), wenn auch nicht immer mit technischem Erfolg.

Für die Bearbeitung aller dieser ihn nahe angehender Vorgänge ist der praktische Chemiker die erste Instanz. Die Zeiten, wo eine hierfür erforderliche bescheidene mikroskopische Schulung als unnöthiger Luxus betrachtet wurde, sind vorüber. Andererseits müssen entsprechend eingerichtete Hochschullaboratorien dem studirenden Chemiker Gelegenheit zu einer Orientirung, dem Forscher solche zu wissenschaftlichem Arbeiten bieten; sich der gewerblich wichtigen Organismen zu erinnern, ist nicht zum wenigsten Aufgabe gerade der Technischen Hochschulen.

\section{Das Waarenzeichengesetz rom}

12. Mai 1894 und die chemische Industrie. Von C. Bloch, Berlin.

Meine Herren: Am 1. Octobor 1894 ist das Gesetz zum Schutze der Waarenbezeichnungen in Kraft getreten, welches im Gegensatz zu dem Gesetz über den Markenschutz vom 30. November 74 auch Worten einen gesetzlichen Schutz einräumte und hierdurch für die chemische Industrie von grosser Bedeutung wurde. Von den bis zum 1. Januar 1900 eingetragenen ca. 14000 Wortzeichen gehören ca. 8500 der chemischen Industrie im weitern Sinne an, und ist schon allein hieraus die Bedeutung des Gesetzes für diese Interessentenkreise erkennbar. Dieser Bedeutung entsprechend waren nun aber auch die Anforderungen, die das Gesetz an die einzutragenden Zeichen stellte, erheblich erhöht worden, und sind dieselben schon heute nach 6-jäbrigem Bestehen des Gesetzes so schwer erfüllbar, dass sich sogar in letzter Zeit einzelne Industrielle dazu verstanden haben, öffentliche Concurrenzen zur Erlangung entsprechender Waarenzeichen auszuschreiben. In Anbetracht dessen verlohnt es gewiss der Mühe, sich mit den Bedingungen, welche das Gesetz an ein einzutragendes Zeichen stellt, näher bekannt zu machen, und will ich nun die gesetzlichen Bestimmungen, wie sie rom Kaiserlichen 